\title{
MARCANDO DIFERENÇAS PARA FORJAR SEMELHANÇAS
}

\author{
Os descendentes de imigrantes \\ italianos em Caxias do Sul - RS
}

Miriam de Oliveira Santos *

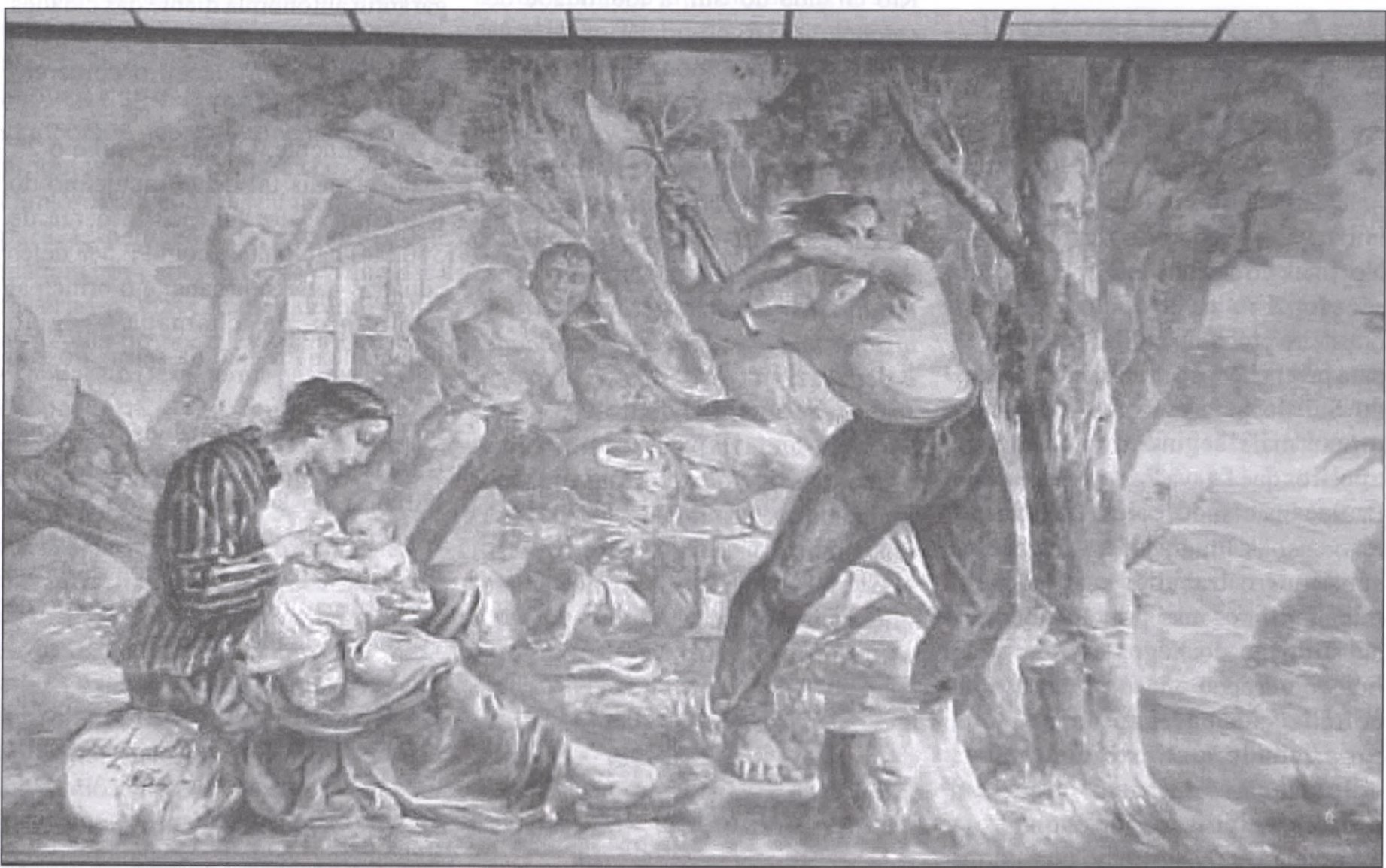

Painel de Aldo Locatelli, fotografado por Miriam de O. Santos

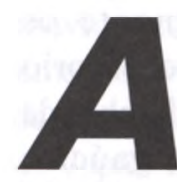
cidade de Caxias do Sul costuma ser referenciada como um modelo da imigração italiana para o Rio Grande do Sul. Se a palavra "modelo" for interpretada como um padrão desejado, um exemplo a ser seguido, pode até ser. Se pensarmos em Caxias do Sul como um "tipo- ideal" weberiano, estaremos muito longe da verdade, porque a colonização de Caxias do Sul possui inúmeras particularidades em relação às demais.

Se pensarmos na definição de grupo étnico de Seyferth (1986, p.530) em que ela aponta como fundamentais tanto uma identidade distintiva atribuída, quanto uma cultura, origem e história comum, verificaremos que a rigor não se pode categorizar os descendentes de imigrantes italianos de Caxias do Sul, como um grupo étnico, já que lhes falta uma identidade distintiva atribuída. No entanto a mesma autora ao definir etnia afirma que este termo "é empregado na literatura antropológica para designar 
um grupo social que se diferencia de outros grupos por sua especificidade cultural." (Seyferth, 1986, p.435) Portanto, de maneira análoga a que Morales aplica aos nordestinos na feira de São Cristóvão do Rio de Janeiro, podemos alegar que: "a rigor não se está tratando de etnicidade nem de grupo étnico. Mas, numa visão de dentro, (...) se vê que o grupo (...) tem uma lógica e valores diferentes do grupo que o circunda." (Morales, 1993, p.6)

\section{A Colonização Italiana no Rio Grande do Sul}

Desde o início, colonização e imigração são conceitos entrelaçados. No final do século XIX e início do século $\mathrm{XX}$, o governo imperial brasileiro procurou utilizar a imigração para preencher os vazios demográficos do Sul do país e ao mesmo tempo tornar mais seguro o caminho de tropeiros que ligava Porto Alegre a São Paulo, instalando colônias nas suas margens. A Imigração visava não só substituir o trabalho escravo pelo trabalho livre, mas principalmente a substituição do negro escravo pelo branco europeu em um processo de colonização baseado na pequena propriedade. Neste contexto a colonização era vista como um processo civilizatório, enquanto a escravidão era vista como uma forma arcaica de produção que não combinava com a modernidade.

A opção inicial foi por colonos alemães, mais tarde em função da proibição, por parte do governo alemão, da imigração para o Brasil, a opção recaiu, preferencialmente, por colonos do norte da Itália.

A Itália era um dos países mais pobres e populosos da Europa, com enorme oferta de mão-de-obra. As guerras para a unificação, a ocupação por sucessivos exércitos, o serviço militar por três anos consecutivos, foram fatores que contribuíram para a desorganização da unidade familiar de trabalho e para a pauperização do pequeno agricultor. Por outro lado, a industrialização da Itália Setentrional não era capaz de absorver toda a mãode-obra disponível, o que explica a opção pela migração.

Esses camponeses italianos adquirirão, ao chegar no Nordeste do Rio Grande do Sul, a identidade de colonos, isto é, proprietários de uma fração de terra denominada colônia. Segundo Seyferth (1993, p.38) " No seu significado mais geral, a categoria colono é usada como sinônimo de agricultor de origem européia, e sua gênese remonta ao processo histórico de colonização (...)" e ainda "A categoria colono foi construída, historicamente, como uma identidade coletiva com múltiplas dimensões sociais e étnicas" (Seyferth,1993, p.60).

Sendo assim, a palavra colono, que era a designação oficial para o imigrante que adquiria um lote de terra em um projeto de colonização, converte-se em um símbolo de diferenciação étnica.

\section{Caxias do Sul: de colônia a metrópole}

Situada na Região Nordeste do Estado do Rio Grande do Sul, a cidade de Caxias do Sul surgiu em 1875, como núcleo urbano de uma colônia de imigrantes italianos. Em abril de 1884, passou a constituir o $5^{\circ}$ distrito municipal de São Sebastião do Caí, deixando a condição de colônia. Em 20 de junho de 1890 foi criado o Município de Caxias com foro de Vila.
Em 1910, no mesmo ano da inauguração da ferrovia, foi elevada à cidade.

Com a ferrovia, Caxias adquiriu um lugar relevante na vida comercial da região de colonização italiana, substituindo o porto fluvial de São Sebastião do Caí. A cidade transformou-se num centro de produção agrícola e de intenso comércio, funcionando como entreposto entre os Campos de Cima da Serra, as demais colônias e a capital. Essa posição privilegiada lhe garantiu autonomia diante das cidades vizinhas, garantiu sua expansão econômica e fortaleceu o comércio local (Heredia, 1997).

Atualmente, Caxias do Sul é o $2^{\circ}$. maior e mais influente município do Rio Grande do Sul, possui cerca de 360.000 habitantes, com $92,5 \%$ deles situados na área urbana; é o principal município da chamada "região italiana" ou "região da serra" do Rio Grande do Sul.

Um dos fatores que diferencia Caxias do Sul das demais colônias italianas do Rio Grande do Sul é a existência de uma próspera burguesia industrial, que se apropriou da Festa da Uva e a utiliza como elemento de afirmação de identidade étnica.

Ao contrário de outros lugares do Brasil onde houve influência da colonização italiana, Caxias do Sul é uma cidade de porte médio. A cidade cresceu sob a hegemonia da população italiana e à medida em que cresceu e se industrializou, começou a atrair "estrangeiros". Inicialmente os colonos da região rural do próprio município e de municípios vizinhos da encosta nordeste da serra gaúcha, também de origem italiana, mais tarde esta atração se estendeu à população dos chamados "campos de cima da serra" e às colônias alemães. Segundo "O Pioneiro", o principal jornal da 
cidade, Caxias do Sul é hoje uma cidade em que os migrantes formam a maioria da população.

Outra particularidade importante é que se, de fato, os descendentes de imigrantes italianos não são mais a maioria no total da população, continuam sendo a maioria nas classes mais altas: são eles os donos da maior parte das indústrias e grandes lojas da cidade. Em todos os lugares ostentam orgulhosamente nas fachadas das lojas e fábricas os sobrenomes de seus antepassados: Eberle, Prataviera, Tramontina, Cesa, etc., mesmo nos locais em que a gerência foi profissionalizada e a família se afastou do controle direto.
Num contraponto interessante, as famílias italianas agem como "quatrocentões paulistas", são as famílias "tradicionais" da cidade, os fundadores dos clubes, as damas de caridade, enfim, formam a "elite" da cidade.

\section{A Celebração das origens através da Festa da Uva}

Quando foi criada, em 1931, por um descendente de portugueses, a Festa da Uva era na verdade uma exposição de Castas Viníferas e visava incentivar os agricultores a substituírem a uva Isabel por outras variedades de uva mais adequadas para a produção de vinhos finos. Esta exposição durou apenas um dia e foi batizada de Festa com a finalidade de atrair um público maior.

Se considerarmos o objetivo desta exposição, ela foi um fracasso, já que ainda hoje $80 \%$ da uva plantada na serra gaúcha é da variedade Isabel. Mas a partir da segunda edição, em 1932, ela se transformou realmente em uma "Festa da Uva", contando inclusive com um desfile de carros de boi decorados e, em 1933, a Festa passou a ter também uma rainha. "Coincidentemente" a primeira rainha eleita foi Adélia Eberle, filha de um dos grandes nomes da indústria caxiense que é considerado até hoje

Painel de Aldo Locatelli, fotografado por Miriam de O. Santos

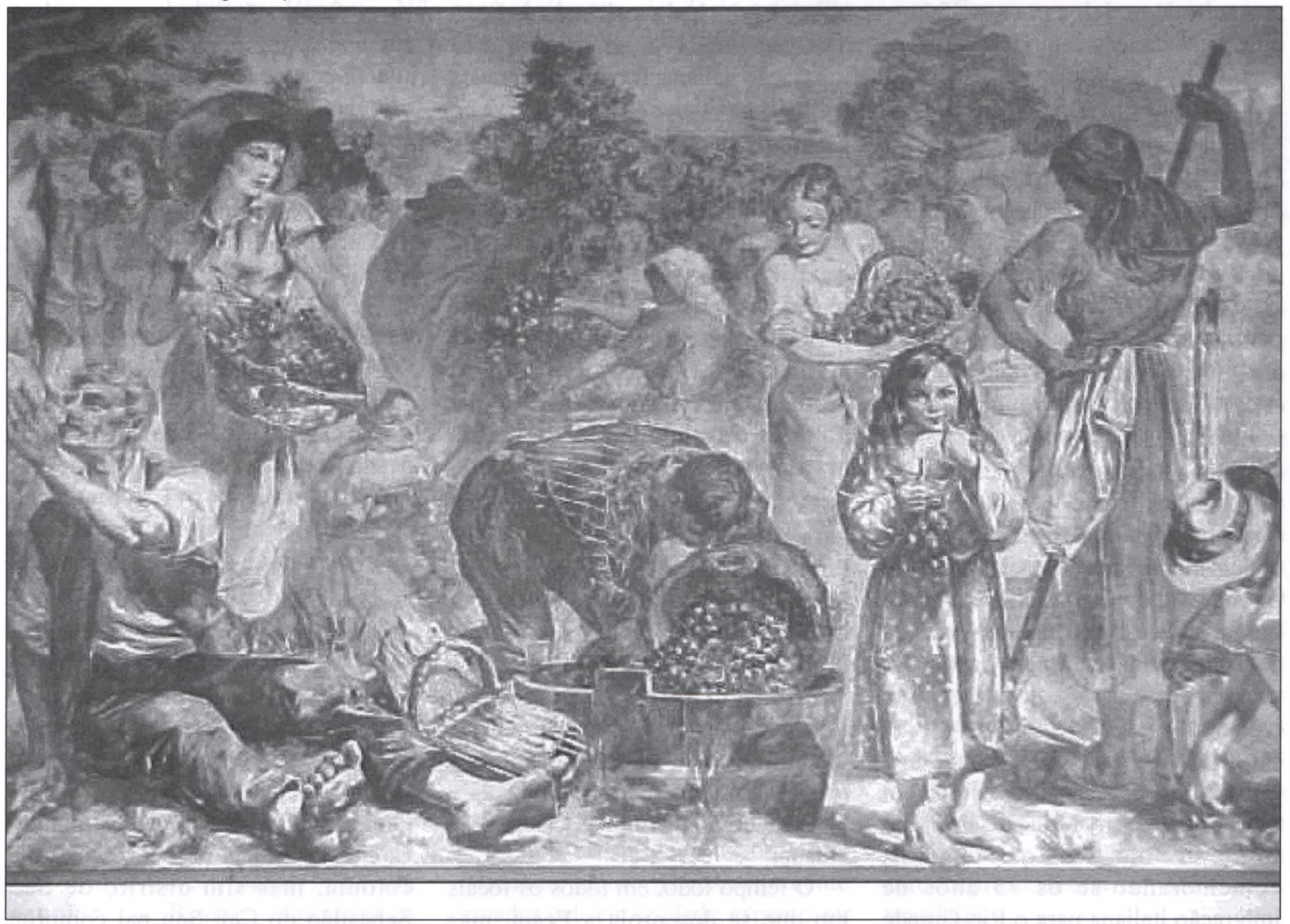


como o modelo de "pioneiro", exemplar acabado de self-made-man.

A grande repressão da campanha de nacionalização brasileira, na década de 30 , aconteceu, principalmente, entre os imigrantes que não falavam português, enquanto a classe mais alta, que era bilíngüe, manteve a cultura e construiu uma identidade diferenciada calcada na etnicidade.

Em Caxias do Sul observamos que justamente durante o período em que a campanha de nacionalização foi mais forte, de 1930 até 1954 , os prefeitos eram descendentes de italianos, inclusive aquele que foi nomeado durante o Estado Novo, Dante Marcucci, que ficou no poder até 1947 , e antes de ser prefeito já havia sido o presidente da Festa da Uva de 1932, acumulando os dois cargos, prefeito e presidente da festa, em 1937.

Em 1975, centenário da imigração italiana em Caxias, o prefeito era Mário Ramos, presidente da Festa da Uva de 1972. O governador do estado na época, Euclides Triches, havia sido prefeito de Caxias do Sul no período de 1951-1954. Observamos que em Caxias do Sul, ao contrário do que ocorria em outras zonas de imigração e colonização, os descendentes de imigrantes detinham tanto o poder político quanto o econômico

São estas pessoas que desde 1932 , mas principalmente a partir de 1950 , vão produzir um discurso sobre a etnicidade italiana e relacioná-la com o progresso de Caxias do Sul. Deste modo, a Festa da Uva é organizada pela burguesia local para cantar em prosa e verso a saga dos "pioneiros italianos".

Depois da festa de 1937, houve uma interrupção da seqüência das Festas em função da II Guerra Mundial. Em 1950 foram retomados os festejos, comemorando-se os 75 anos de imigração italiana para o Rio Grande do Sul e o presidente da república, o Gal. Dutra foi pessoalmente abrir a festa.

Até 1954 , as instalações da Festa eram provisórias, construídas especialmente para a ocasião. Em 1954 foram construídos pavilhões definitivos para a Festa da Uva, enfeitados com pinturas do italiano Aldo Locatelli, que retratam a Imigração Italiana. Nestes pavilhões está instalada, atualmente, a prefeitura municipal. Junto com a Festa da Uva de 1954 aconteceu também a $1^{\text {a}}$ Feira Agro-Industrial e a inauguração do monumento ao imigrante, pelo presidente Getúlio Vargas.

Em 1974 foi criada a empresa "Festa Nacional da Uva, Turismo e Empreendimentos S.A.", tendo como objetivo principal a realização da Festa da Uva. Em 1975, no centenário da imigração italiana, foram inaugurados os atuais pavilhões da Festa da Uva no Parque de Exposições Centenário.

Podemos dizer que ao longo da história as comemorações da Festa da Uva em Caxias do Sul passaram por quatro fases bem marcadas; os historiadores locais utilizam a seguinte periodização: origem, de 1931-1937; afirmação, de 1950-1972; profissionalização, de 1975-1992 e de volta às origens, de 1994 aos dias atuais.

A festa de origem elitista remete para a idéia de distinção entre os descendentes de italianos e os brasileiros, e ao esforço para forjar uma identidade étnica de "ítalosbrasileiros", ou como preferem alguns "ítalos-gaúchos". Neste sentido funciona tanto como festa de produção e como festa de celebração de uma origem comum, sendo organizada e pensada como distintiva pela elite da cidade.

O tempo todo, em todos os locais em que se desenrola a Festa, mas especialmente nos desfiles e nos discursos, exalta-se o colono italiano, o pioneiro fundador da cidade de Caxias do Sul.

\section{O mito do "pioneiro"}

A categoria pioneiro não é exclusividade do discurso dos descendentes de imigrantes italianos, segundo Seyferth (2000, p. 98):

"As representações simbólicas sobre o pioneirismo associado à colonização de terras devolutas marcam as muitas representações de etnicidade de poloneses, alemães e italianos. Um ethos do trabalho, de certa forma vinculado a um ethos camponês, faz parte desse universo simbólico que tem como contraponto a preguiça e a indolência assumidos como atributo característico do 'brasileiro' ( ou caboclo). Na representação do pioneiro, a categoria colono (trazida do jargão oficial) identifica os imigrantes europeus $e$ seus descendentes, e a colonização é definida como um processo civilizatório instaurado na selva brasileira."

No caso de Caxias do Sul forma-se desde cedo uma elite dirigente na cidade, tanto política como economicamente falando e é esta elite que vai impor a sua visão de mundo, bem como o mito de origem do "pioneiro", do "colono italiano" em contraste com os "selvagens" da terra.

Citamos, anteriormente, o caso de Ábramo Eberle visto como pioneiro exemplar, o colono que se tornou industrial. Será mesmo? Eberle chegou ao Brasil em 1884 quando Caxias do Sul já não era mais uma colônia, mas sim distrito de São Sebastião do Caí. Seu pai comprou 
dois lotes: um urbano, onde instalou uma serralheria, e outro rural. Ábramo, seus irmãos e sua mãe instalaram-se no lote urbano e quando, anos depois, o pai decidiu retirar-se com a família para o lote rural, Ábramo, já adolescente, permaneceu na cidade assumindo a serralheria

Outro mito recorrente é o da estrada aberta a facão. Correm na região inúmeras narrativas sobre a maneira como os pioneiras subiram a serra carregando seus pertences e abrindo caminho na mata a golpes de facão. Há aqui um equívoco, não de todo isento de má fé, já que a primeira ligação entre os campos de Viamão (onde atualmente fica Porto Alegre) e São Paulo foi a Estrada Real, concluída em 1736, um ano antes da fundação do estado do Rio Grande do Sul. Desde 1864 existiam estradas ligando as colônias alemãs aos campos de Cima da Serra, tanto para Vacaria quanto para São Francisco de Paula.

$O$ percurso que os colonos faziam era de barco de Porto Alegre até São Sebastião do Caí e depois em estrada carroçável até o Barracão ${ }^{1}$. De lá sim, abriam caminho a facão até os seus lotes, penoso com certeza, mas evidentemente bem menos que os propalados cento e poucos quilômetros serra acima.

Desde sempre um local de passagem, uma encruzilhada em um caminho de tropeiros, a cidade de Caxias do Sul nunca foi uma comunidade perdida e isolada no meio do mato como rezam as lendas dos pioneiros.

\section{Conclusão}

O “apagar" das diferenças é muitas vezes provocado justamente pelo fenômeno de "invenção da tradição", ao contar "antigamente era assim" misturam-se costumes e acontecimentos de épocas e lugares diversos e unifica-se a memória coletiva em torno de um repertório comum. Sendo assim, as lembranças dos pioneiros que desmataram o lugar passam a ser as de todo o grupo de imigrantes, não levando em consideração o fato de que a região onde atualmente se situa Caxias do Sul foi palco de imigrações fracassadas por parte de alemães, poloneses e franceses, antes da imigração italiana, e que muitos italianos chegaram à cidade na década de 30 , quando ela já era um florescente pólo industrial ou após a $2^{\mathrm{a}}$ Guerra Mundial, quando a indústria metal-mecânica já havia se consolidado na região.

Mesmo o que é apontado como sinal de formação de uma rede de solidariedade pode ser sinal de divisão. É o caso das numerosas "capelas", apontadas como sinal da importância da religião católica para a manutenção da identidade italiana entre os colonos quando, na verdade, muitas delas se originaram a partir de brigas internas dentro de um mesmo grupo, às vezes simplesmente por uma questão de honra em criar uma capela e um salão de festas mais vistosos que aqueles construídos pelo grupo de origem.

Por outro lado, a evocação ao ethos do trabalho como uma característica étnica pode levar não exatamente a uma solidariedade, mas a uma preferência por trabalhadores de "origem" européia e ao preconceito contra "brasileiros". Ao explorar a divisão italianos/brasileiros encobre-se uma outra divisão a de patrão/ empregado. Entre os pouquíssimos registros de movimentos operários em Caxias do Sul destaca-se o dos tanoeiros portugueses, que por sinal organizaram não só o primeiro sindicato da cidade, como a $1^{\text {a }}$ greve em 1930. Para os imigrantes italianos e seus descendentes restaram os papéis de "bons trabalhadores", "dóceis" e "cumpridores dos seus deveres", a etnicidade é acionada como um diferencial que ajuda a construir uma auto-imagem positiva do grupo e a justificar a prosperidade dos descendentes de imigrantes em contraste com os demais grupos.

\section{* Miriam de Oliveira Santos é Mestre em Ciência Política pela UFRS, Doutoranda em Antropologia Social no PPGAS do Museu Nacional/UFRJ e Pesquisadora Associada ao Núcleo Interdisciplinar de Estudos Migratórios - NIEM-RJ.}

\section{NOTA}

1- Local onde ficavam abrigados os colonos que aguardavam a distribuição dos lotes.

\section{REFERÊNCIAS BIBLIOGRÁFICAS}

HERÉDIA, Vania Beatriz Merlotti

(1997) Processo de Industrialização da Zona Colonial Italiana. Caxias do Sul, EDUCS.

MORALES, Lúcia Arraes

(1993) A Feira de São Cristóvão: Um estudo de identidade regional. Dissertação de Mestrado, Rio de Janeiro, PPGAS-Museu Nacional/ UFRJ.

SEYFERTH, Giralda

(1986) "Grupo étnico", "Etnia” (verbetes) In: Dicionário de Ciências Sociais. Rio de Janeiro, Fundação Getúlio Vargas/MEC.

SEYFERTH, Giralda

(1993) "Identidade Camponesa e Identidade Étnica - Um estudo de caso". Anuário Antropológico 9/1.

SEYFERTH, Giralda

(2000) "Identidade Nacional, Diferenças Regionais, Integração Étnica e a Questão Imigratória no Brasil". In: Região e Nação na América Latina. George de Cerqueira Leite Zarur (org.), Brasília: UnB. 